\title{
Cardiovascular Diseases and Public Health
}

\author{
By JOHN W. FERREE, M.D., M.P.H.
}

- One out of every sixteen persons in the United States has some form of cardiovascular disease.

- One out of every two deaths in this country is from a disease of the heart or blood vessels.

- Approximately 176 million workdays are lost yearly because of heart disease.

- Cardiovascular diseases accounted for the major or secondary impairment in more than 42 percent of those receiving aid under the Bureau of Public Assistance of the Social Security Administration program for the permanently and totally disabled, as shown in a cross-section survey.

- Cardiovascular diseases are long-term diseases; hypertension, for example, has an average course of 20 years.

- In the general population, 3 percent of untreated streptococcal infections are followed by rheumatic fever; among those who have had rheumatic fever, the figure can be as high as 50 percent.

- $A$ recent study of the caseload of the Instructive Visiting Nurse Association in Baltimore indicated that 46 percent of the nonmaternity cases had some disease of the heart or circulatory system as the principal diagnosis.

Dr. Ferree is director of community services and education, American Heart Association, New York, N.Y. He was formerly State health commissioner of Indiana.

Vol. 71, No. 2, February 1956
All these are persuasive--if coldly statistical-reasons for firmly placing the cardiovascular diseases in the public health domain. The American Heart Association has long recognized the public health implications of heart disease, and the concept of community responsibility in prevention, diagnosis, treatment, and education is basic to its philosophy.

The association regards the person with heart disease as a person with social, economic, and personal problems which bear not only on himself and his family but on the community as well. It follows that these problems lend themselves in great measure to successful attack by organized community effort, long accepted as a criterion for public health action. These cardiovascular disease problems, then, are definitely a public health responsibility.

\section{History}

Community action to help the cardiovascular disease patient has from the start been one of the primary concerns of the American Heart Association.

The first organized effort to collect and apply information on heart disease was made by a group of New York physicians whose interest was sparked by pioneer cardiac rehabilitation work being done at Bellevue Hospital. In 1916 , they formed the "ancestor" of the $\mathrm{AHA}$, the Association for the Prevention and Relief of Heart Disease. Dr. Haven Emerson, then commissioner of health in New York, was a leading spirit of the movement. 
One of the association's first actions was to encourage formation of cardiac clinics similar to the one at Bellevue. Soon 20 clinics were functioning in hospitals and outpatient departments.

Aside from clinic work, the young organization busied itself with fulfilling its other goals and purposes:

"To gather data from wide sources and arrange for its practical application, in education, occupation, and social welfare; to study and develop occupations and vocational guidance for cardiacs; to take a formative interest in workmen's compensation insurance and similar problems affecting cardiac patients; to work constantly for the prevention of heart disease through the dissemination of information and the application of preventive means (as in increased facilities for postrheumatic throat and dental treatments); to organize cardiac convalescence to provide larger opportunities in existing institutions, especially for youth; to assist in coordinating the various efforts in this field as made by health departments, schools, cardiac classes, special investigators, the Trade School for Cardiacs, etc.; and to encourage the formation of branch associations."

By the early 1920's, physicians throughout the country had become interested in the association's work. Accordingly, the New York group invited about 100 physicians to a meeting in St. Louis on May 24, 1922, to plan for a national organization. Two years later, on May 20, 1924, the American Heart Association was formally incorporated under the laws of New York State.

The St. L souis meeting defined the objectives of the projected national organization as follows :

"The function of such an association would be to coordinate all activities bearing on the heart problem, to develop new lines of research, to collect and distribute information, to further public health and industrial education, and to develop a sound public opinion as to the true meaning and seriousness of the problem."

Not all of these objectives could be carried out immediately. For more than two decades, the association performed important professional functions. It published a scientific journal, held an annual 2-day scientific meeting, and established standards in such technical matters as clinical electrocardiography and blood pressure readings.

Of particular significance were the early and continuing achievements in standardizing nomenclature and criteria for diagnosis of cardiovascular diseases. The first work in this area was done in 1916; it has been carried on by the New York Heart Association, which publishes "Nomenclature and Criteria for Diagnosis of Diseases of the Heart and Blood Vessels." With uniform standards, we were able to learn more precisely the nature and size of the problem we were dealing with.

As more knowledge became ours, two basic facts that were responsible for the association's ultimate change of course began to stand out: (a) that the heart and blood vessel diseases constituted a problem of far greater magnitude than had been supposed, and $(b)$ that much could be done to control these diseases, that the old fatalism could well be replaced by hope and optimism.

From these two premises, it was clear that the public health responsibilities which the association had set out for itself had become even more pressing. Yet the association, a small grou? of physicians and scientists, was not organized to cope with the multiple problems which cardiovascular disease poses for the individual, his family, and the community, nor was it equipped to get its message of hope to the people.

Moreover, a full-fledged program of research was mnperative if the war on heart disease was to move ahead. By the 1940's, research had already contributed to the feeling of optimism regarding heart diseases-cardiac surgery, penicillin and sulfa drugs for the prevention of rheumatic fever and subacute bacterial endocarditis-and it could be counted on to produce other advances.

The time had come for a broad community approach to the cardiovascular diseases. Addition of the lay public to the ranks of those already fighting heart disease was the logical first step. Citizen support was needed to finance research, for the channeling of new and existing information to the public as well as to professional groups, and the development of community services for the patient with heart 


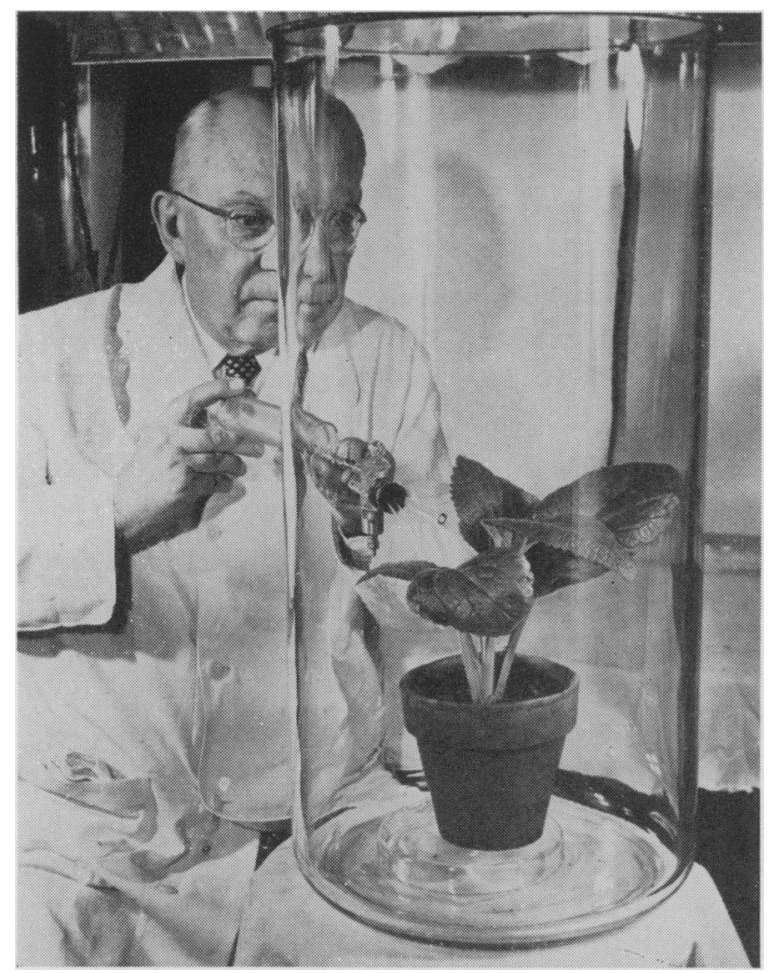

Foxglove plant "breathing in" radioactive carbon dioxide syringed into surrounding bell jar. Radioactive digitalis will be prepared from the dried leaves for use in tracer studies.

disease. And, certainly as important, informed laymen were needed to organize and coordinate community programs all over $\Lambda$ merica.

In 1948 the American Heart Association was expanded into a voluntary health agency, the only national voluntary health agency devoted exclusively to combating diseases of the heart and circulation. Laymen and professional persons not previously eligible were admitted to membership and to places on the association's governing bodies for the first time.

It present the $\triangle H \Lambda$ and its affiliates have a voting membership of about 25,000 , almost evenly divided between physicians and laymen. There are now 56 direct affiliates and more than 350 local chapters, which are largely autonomous in developing programs to meet their own community needs. The national headquarters in New York administers the national phases of the program, maintains a clearinghouse of ideas and suggestions for the work of State and local associations and committees, and provides educational and program guidance materials and services for them.
The program activities of the American Heart Association are financed primarily by public contributions made during the annual February Heart Fund campaign. At least half of the funds received by the national office are spent to support research, which has top priority in the program as the single most important factor by which we hope to conquer or control the heart diseases.

But results of research do not automatically become full-fledged community programs for helping people with cardiovascular disease. And the encouraging news of scientific progress does not announce itself to those who should hear it. To reach them, an educational program is needed.

Guiding the association's triple program of research, community service, and education are three councils, each directly responsible to the board of directors of the association. They are the Scientific Council, the Council on Rheumatic Fever and Congenital Heart Disease, and the Council on Community Service and Education. The councils are subdivided into committees made up of specialists in their particular fields, who, through their combined experience, are able to give advice and guidance on heart programs.

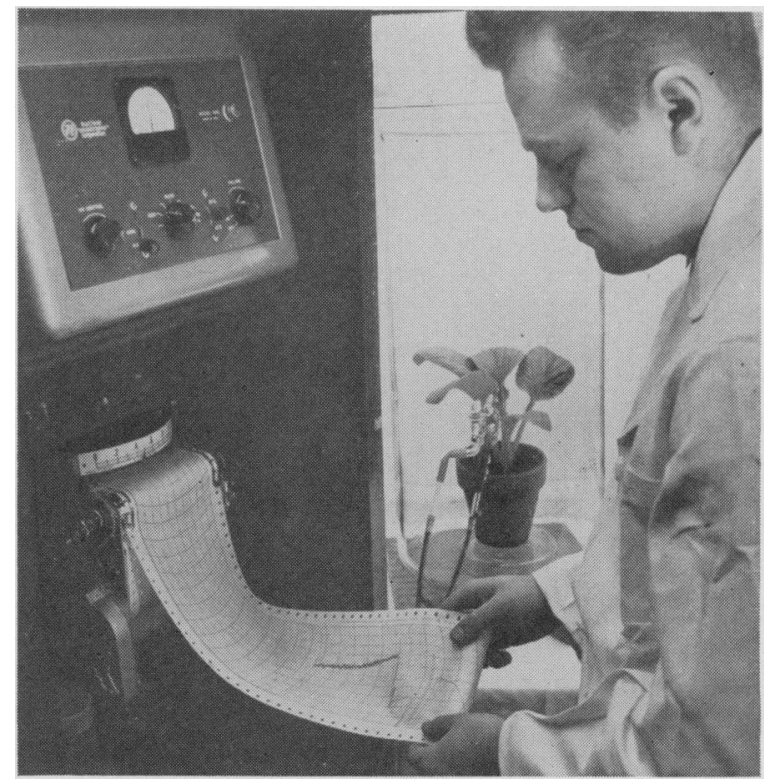

"Tracer" digitalis enables researchers to follow the drug and to study its action after it enters body tissue. 


\section{Research}

Since 1948 , a total of approximately $\$ 13$ million has been allocated by the American Heart Association, its affiliates, and their chapters for research support. Iffiliates and chapters which make research awards in their own areas do so in addition to their contribution to the national research fund.

The association offers research support at three levels: research fellowships and established and career investigatorships.

Research fellowships are granted to young men at the outset of their careers, for a 1- or 2year term, to enable them to train as investigators under experienced supervision.

Established investigatorships provide support for a 5 -year period to scientists who have demonstrated their capacity in research and have developed to the point where they are independent investigators.
Career investigatorships, now held by three men, provide an annual stipend throughout the productive lives of carefully selected scientists of proved and outstanding investigative capacity and genius.

In addition to these three forms of research support, grants-in-aid are awarded to provide the tools of research-technical aid, equipment, and supplies-to experienced investigators working on a specified program of research.

Epidemiological research-studies of diseases of the heart and blood vessels in terms of their incidence and prevalence among population groups with varying characteristics-is beginning to take its place beside basic or experimental research, for which it supplies the clues. For example, the association of overweight and mortality from heart disease was one of the leads that gave impetus to experimental studies of cholesterol and lipoproteins. Similarly,

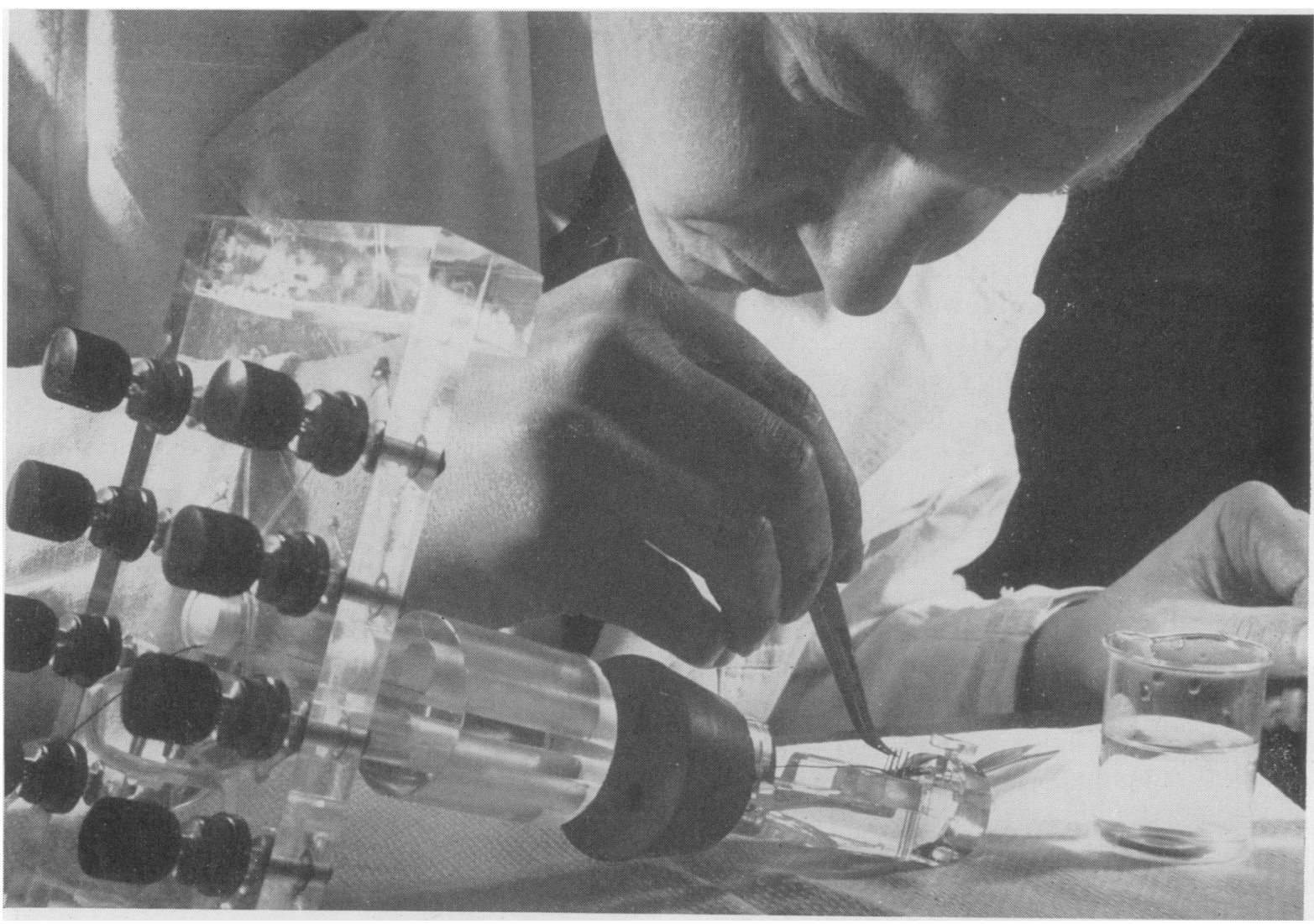

Investigator placing heart muscle between the electrodes of a plastic holder, which will be immersed in vessel of warm salt solution (right) and then stimulated to contract rhythmically. As different drugs are added to the solution, their effect on the muscle's action can be observed in detail by instruments which record the force of its contraction and the electrical impulses generated by it . . . to gain a better understanding of how the heart muscle works and to improve methods for treating it when its pumping action is impaired. 


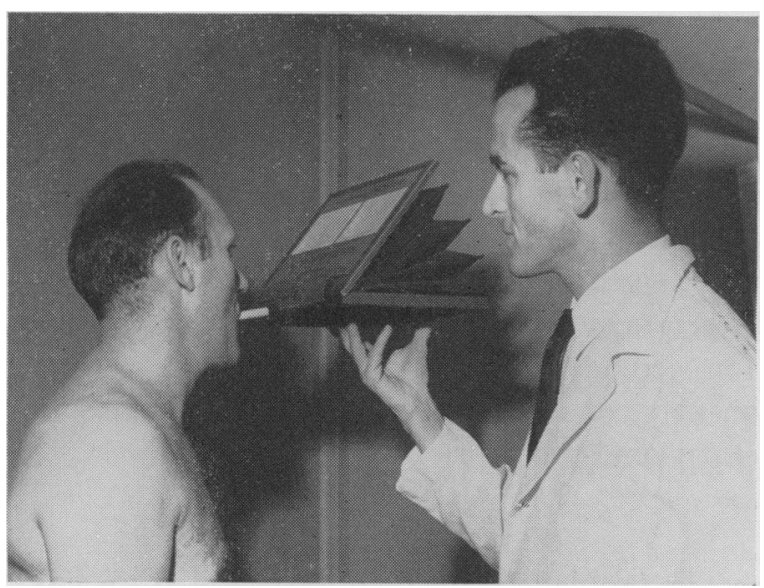

In the "pleated balloon" test, which measures vital lung capacity, patient raises top panel as high as possible. This is part of the Cleveland Area Heart Society's cardiac work classification clinic procedure to help measure the patient's work capacity.

epidemiological evidence established the relationship between streptococcal infections and rheumatic fever.

\section{Community Service}

Although the research programs can be actively participated in by only a few hundred individuals, the AHA's community service program is entered into by thousands of men and women, physicians and laymen alike.

Because they are planned and carried out locally, heart association services vary from community to community. The American Heart Association sets general policies and gives guidance, and the State or regional affiliate gives its support and help, but the actual work is in the hands of the heart association in the community.

A local heart association does not try to solve all of the community's heart disease problems singlehandedly. "Heart disease will not be conquered by the lone wolf approach" has been echoing in heart association ears ever since it was first declared at the First National Conference on Cardiovascular Diseases, held in Washington in 1950 and sponsored jointly by the American Heart Association and the $\mathrm{Na}$ tional Heart Institute, Public Health Service.

In tailoring its programs to the community, a local heart association may work at different times with parent-teacher associations, social work and welfare agencies, labor unions, business and church groups, and other voluntary and official health agencies. It should at all times maintain a close working relationship with the local health department.

A typical community service program might include clinies for patients with cardiovascular disease, rheumatic fever prophylaxis, rehabilitation services and work evaluation units offering to cardiac patients and housewives simpler work methods, vocational counseling, nutritional guidance for patients with heart disease, and home care.

\section{Clinics}

The clinic has long been an important concern of heart associations and frequently serves as a focal point for the entire community program. Although heart associations do not actually operate clinics, they help insure the best possible services for the patient by granting certification to local clinics that meet the standards established by a national AHA committen, as outlined in the AHA booklet, Recommended Standards for Cardiovascular Clinics. In addition, a heart association often buys equipment for a clinic or contributes, on a demonstration basis, toward the salary of a medical social worker, a public health nurse, or other professional worker.

\section{Rheumatic Fever Programs}

Most heart associations are developing community programs for the prevention, control, and treatment of rheumatic fever. Rheumatic fever committees of heart associations work closely with physicians to encourage the widest use of antibiotic preventive techniques presently available. They support community diagnostic services, cooperate with school health authorities to develop screening procedures, and in some cases sponsor traveling clinics for isolated rural areas. Several such traveling clinics have been organized in cooperation with the State or local health department.

\section{Rehabilitation Program}

The cardiac rehabilitation program helps patients with cardiovascular disease to remain independent, self-supporting members of society, thus bringing them psychological as well as eco- 
nomic benefits. A pioneering development in this area is the work classification unit, often attached to a cardiac clinic. Each unit provides a counseling service to which physicians and industry may refer patients with employment problems stemming from cardiovascular disease. Here the patient's work capacity is assessed by a team representing several professional disciplines, as a basis for selective placement in a job where he can perform fully without overtaxing his physical reserve.

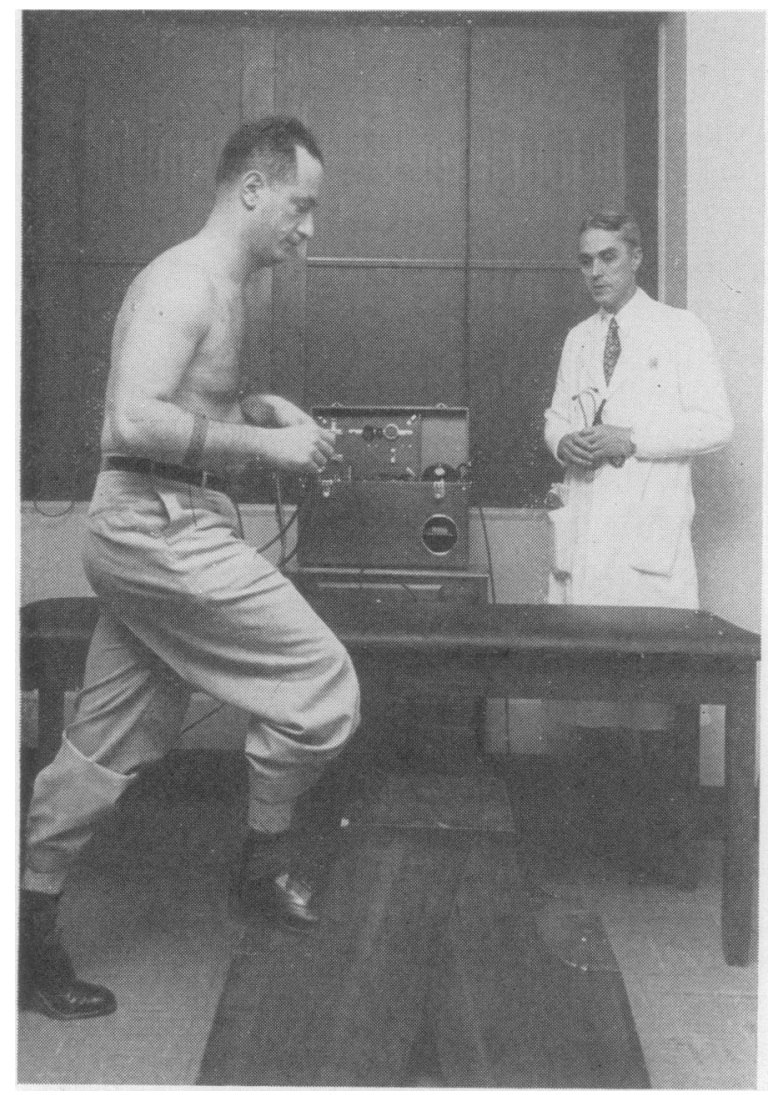

Physician watches the "master two-step exercise test" in the New York Heart Association's work classification unit. Patient climbs the steps, turns around, and goes down 20 times while "hooked up" to the electrocardiograph. Immediately after the exercise he lies down and receives an electrocardiograph examination.

'Together with other services, such as the sheltered workshop and vocational guidance, the work classification unit does much to aid the physician in the practical management of the patient. At the same time it helps to break down the barriers that still keep many capable patients with heart disease from productive employment.

In the "Heart of the Home" program, rehabilitation principles have been adapted to the needs of the housewife with cardiovascular disease. Housewives are taught how to simplify their work habits and conserve their strength. Special courses are given by heart associations for cardiac homemakers and for those who frequently come in contact with them-nurses, occupational therapists, home visitors.

\section{Nutrition Program}

The problems of overweight and diet have occupied the attention of many local heart associations. A number of heart associations, working with their health departments, have organized weight-control groups, and several have given low-sodium-diet cooking classes.

On the national level, the American Heart Association, in cooperation with the Council on Foods and Nutrition of the American Medical Association and the Food and Nutrition Board of the National Research Council, developed recommendations for more precise labeling of the sodium content of special dietary food products, which were incorporated in 1954 in the official regulations by the Food and Drug Administration. Although neither the American Heart Association nor its branches approve or disapprove of specific dietary food products, local heart associations should be able to refer patients to sources of dietetic foods in the community.

\section{Chronic Illness}

Another area of community service concerns chronic illness. Home care programs are being explored now as a way for heart associations to cooperate with other community groups in such projects.

In whatever ways a heart association carries out its program, the underlying philosophy is one expressed by Dr. Martin Cherkasky, chairman of the Council on Community Service and Education: "To help those who suffer from heart disease reap the benefits of ever-expanding knowledge, to help them meet the practical problems which illness creates for most individuals, to help them learn the message of hope which the achievements of recent years fully 


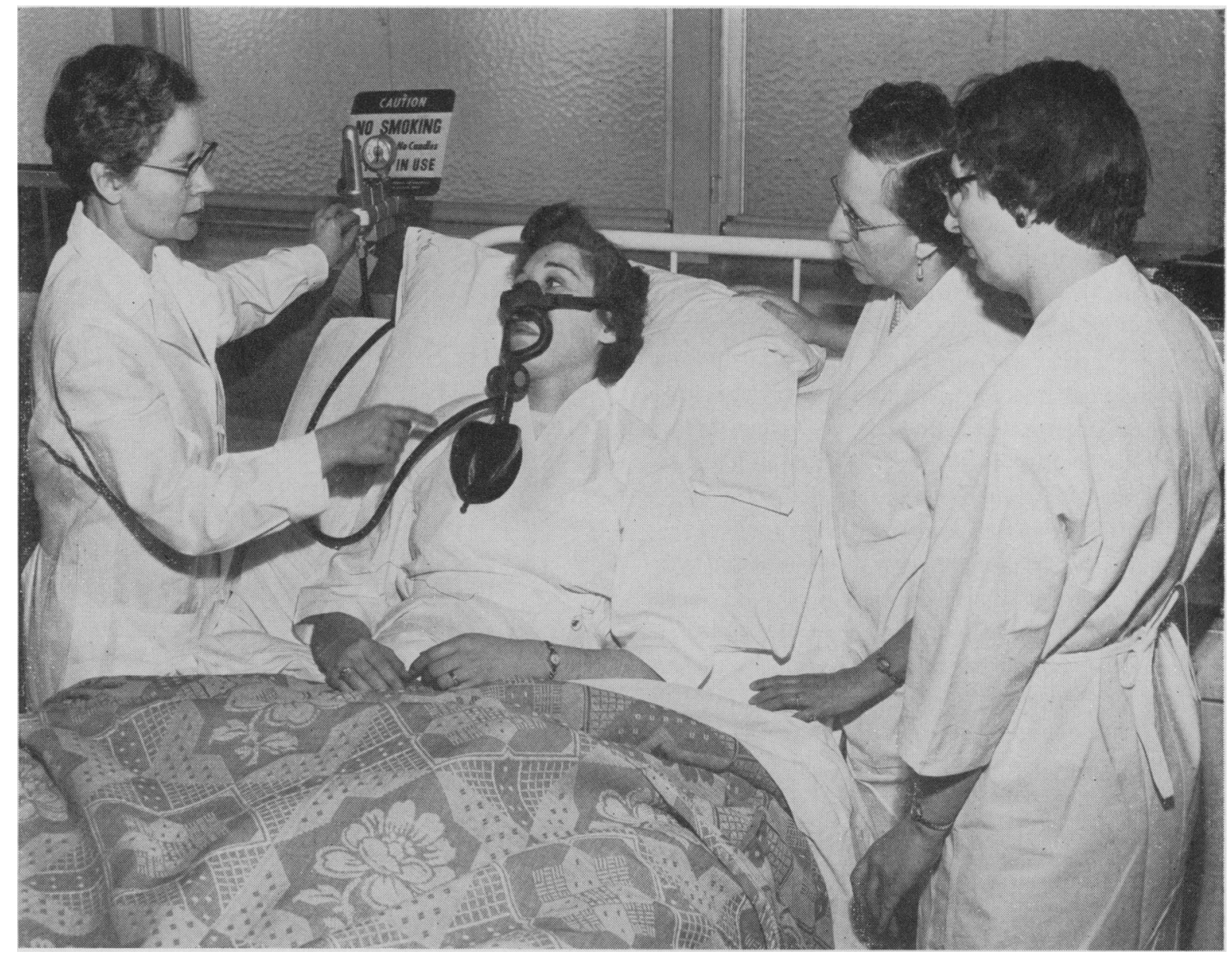

Work conference sponsored by the Washington State Heart Association in cooperation with schools of nursing and the State health department. Special training courses, workshops, and work conferences such as this improve nursing care for cardiac patients.

justify-these are the goals of the association's program of community service and education."

\section{Education}

The educational efforts of the American Heart Association fall into two main categories-programs directed at physicians and other professional groups (nurses, dietitians, teachers, clergymen) and programs directed at the general public and special lay groups (parents, patients, workers).

The $\mathrm{AHA}$ education program for physicians is designed to make available the mass of new and existing knowledge in the field of cardiovascular disease. The annual scientific sessions are probably the most comprehensive presentation of developments in cardiology. In addition, affiliated and local heart associations schedule scientific meetings, forums, postgraduate courses, and other events for the medical profession in their areas, often in cooperation with the local health department and medical societies.

Publications for physicians include two scientific journals, Circulation, a monthly, and Circulation Research, a bimonthly. These have become outstanding media for reports on clinical and basic science subjects. In addition, the bulletin, Modern Concepts of Cardiovascular Disease, reviews a specific cardiovascular subject each month.

Handbooks, manuals, and other materials are also issued to help physicians. These include recommendations for blood pressure determination and for examination of the heart; the previously mentioned book on nomenclature and criteria (prepared by the New York Heart 
Association), standards for electrocardiography, and recommendations on cardiac catheterization and angiocardiography.

Audiovisual tools for medical teaching and meetings are a recent development. They include heart models, films, slides, tape recordings of normal and abnormal heart sounds, a threedimensional visual kit (Cardio-Views), and an audiovisual kit (Cardiac Clinic), which combines slides and a recorded medical discussion.

Most heart associations plan educational meetings, forums, and workshops for other professional groups. Frequently, as in workshops in cardiovascular nursing, these are held in cooperation with the health department and other community agencies and organizations.

Several heart associations have held pastoral counseling meetings for clergymen; and many have brought together groups of teachers, social and vocational workers, occupational and physical therapists, and dietitians and nutritionists to discuss the needs of the cardiac in relation to their particular profession. A number of heart associations conduct special industrial education programs to tell both workers and employers the "cardiac can work" story.

The public education program of the association, conducted on the national and local levels, has been a major factor in creating a climate of optimism and confidence that grows out of a rational understanding of heart disease. Booklets and pamphlets, films, exhibits, and meetings are planned to stress accurate information without exaggeration or distortion, to correct misconceptions, to substitute encouragement and realistic hope for the fear and fatalism of the past, to emphasize the scope of the cardiovascular problem and the belief that heart disease can ultimately be controlled through research, and to urge prompt and proper treatment of heart and circulatory disorders.

The national office provides the general reader with a continuing progress report on advances in the heart program through its quarterly periodical, The American Heart, and through its press information services.

Both the national office and its local associations maintain inquiry services to answer specific questions from individuals and professional persons in need of information and ad- vice. In addition, most local heart associations maintain a speakers bureau to provide wellinformed public speakers, usually physicians, to interested groups.

\section{Association-Health Department Relation}

At about the same time the American Heart Association became a voluntary health agency, the National Heart Institute came into being as one of the National Institutes of Health. In 1950, lay and professional leaders of the two groups met together in Washington for the First National Conference on Cardiovascular Diseases "to determine what we know about cardiovascular disease and how we can apply this knowledge to prevent and cure it." What came out of the conference became the basis for much of the work that both groups have since done.

This past year, the National Heart Institute and the American Heart Association undertook an educational campaign against rheumatic fever, jointly preparing materials for distribu tion to health departments and heart associations. The basis of the campaign is a 4-page statement by the $\mathrm{MHA}$ Council on Rheumatic Fever and Congenital Heart Disease, entitled "Prevention of Rheumatic Fever and Barterial Endocarditis 'Through Control of Strep)tococcal Infections." This was issued first in 1958 and revised in 195\%. Other educational materials in the "Stop Rheumatic Ferer" unit. (1) include a black-and-white film, discussion guide, and leaflets.

The Manual on Administration and Organization for Affiliates of the American Heart Association clearly spells out the heart association-health department relationship:

"Official agencies are legally charged with the responsibility of protecting the public's health. Heart associations have voluntarily assumed a share in this responsibility and should work closely with official agencies toward their common goal.

"Any programs undertaken by a heart association should be brought to the attention of the health department. A number of health departments have developed extensive programs for the control of heart disease. Because these programs, like those of heart associations, 
are financed by public funds, both agencies are responsible for seeing that the funds are not wasted through overlapping or competitive programs.

"A practical arrangement is to have an officer or board nember of the heart association on the health department's advisory committee and to have a member of the board or staff of the health department on the board of the heart association.

"This does not mean that every enterprise must be a joint one; each agency maintains its identity and individuality because each has something different to offer. The broad community representation in the heart association makes it possible for the association to furnish leadership, to act as a pioneer in program development, and to stimulate the official agency to make the best possible use of its resources of money and personnel. Very often the two agencies working together can accomplish more than they could achieve separately."

How does this statement work in practice?

In New York staff members of the statewide heart affiliate spend 2 or 3 days each year in meetings with representatives of the State health department, welfare department, and division of rocational rehabilitation. It these meetings, government and heart association persommel exchange ideas and information on rehabilitation, public health nursing and education, school health, chronic disease, and other areas of mutual concern.

Not only do the groups find they understand each other better, but often new programs develop as a result of these sessions. From the liaison in New York, the heart affiliate undertook a demonstration project in rehabilitation at the suggestion of the State health department. The health department will take over the project-paying the salary of a rehabilitation counselor on the health department teamat the end of the 3-year demonstration period.

Sometimes the financial responsibility for projects is reversed, as in the cardiac work classification unit of the Ileart Issociation of Southeastern Pennsylvania. The Pennsylvania Department of Health finances the unit, which provides for service to individuals whose employment problems are caused by cardiovascular disease.
One of the reasons heart associations find it so important to work with their local health departments, medical societies, and other groups stems from the AHA policy of spending money not for individual care but for community programs in cooperation with others, for demonstration projects where needed facilities do not exist, or for salaries and equipment to supplement the services of some other agency.

Behind this policy is the belief that the association's purposes will not be best served by giving financial aid to individuals to cover the costs of medical or nursing care, hospital bills, or drugs. 'Tremendous sums, far greater than those arailable to the association, would be necessary to meet such requirements on a fair and comprehensive basis. Moreover, diverting the association's limited funds to comparatively few individual patients would undermine its ability to carry out the program it has evolved to benefit all heart patients and to reduce cardiovascular disease as a threat to the Nation's health.

\section{Health Department Problems}

The American Heart Association recognizes the difficulties faced by health departments in meeting the problems of cardiovascular diseases. Shortage of funds, insufficient personnel, hands full just keeping up the traditional health department functions-these are familiar conditions. Yet, as the communicable diseases fade as a major health problem and the chronic illnesses take their place, changes will be appropriate and possible.

A recent study made in Buffalo, $\mathrm{N}$. Y., reveals that crowding, water supply, and sewage disposal have little bearing on four of the most frequent causes of death-heart disease, cancer, stroke, and diabetes (2). Certainly this is not to say that health departments should lessen their vigilance on the old problsms. They will still be with us. And, as the Buffalo study also shows, deaths from infective and parasitic diseases are related to housing, water, and sanitation. But in time, control of these will be left-hand functions of the health department. As the chronic illnesses become more pressing problems, the emphasis will shift.

Until public awareness and financial re- 
sources and sufficient personnel make the shift possible, what can a health department do so far as cardiovascular diseases go?

A health department, with little or no extra expenditure of time, money, or energy, can accomplish much simply by becoming heart conscious-being aware of the entire cardiovascular problem and letting this awareness pervade thinking and planning in all service and education programs:

Films taken in mass $\mathrm{X}$-ray surveys can be read for possible heart disease and suspected cases followed up for diagnosis and treatment.

In prenatal clinics, special attention can be paid to pregnant women who have congenital or acquired heart disease.

Programs to control communicable diseases can include control of streptococcal infections.

Laboratory facilities can be used for blood sedimentation rates and antistreptolysin-O titers in suspected rheumatic fever and throat cultures in suspected streptococcal infection; laboratory technicians can be trained in prothrombin-time determination.

Nursing and convalescent homes can be inspected from the point of view of nutritional requirements and physical limitations of cardiovascular patients.

In nutrition programs, emphasis can be placed on counseling as regards various nutritional needs, such as the low-sodium diet for hypertension and congestive heart failure, and on problems of overweight.

In school health surveys, children with congenital or rheumatic heart defects can be discovered. Through followup services they can obtain the care and management possible through a greatly expanded knowledge in the two fields. It is here that the Crippled Children's Program has so much to offer.

Public health nurses can be instructed in the nursing care of cardiac patients.

A clearer picture of the cardiovascular problem can be obtained through careful recordkeeping.
In all health education programs, cardiovascular disease can be treated to dispel fear and replace it with a reasonable, more objective viewpoint. Teachers and parents can be informed about the relationship of streptococcal infections to rheumatic fever.

All these are things which health departments can do within their existing framework. A number of health departments, of course, are engaged in major programs related to cardiovascular disease.

The cardiovascular disease studies being conducted in Massachusetts, California, and New York State, among others, are calculated to give us the kinds of information that will more clearly define health department and heart association roles in prevention and control of cardiovascular diseases through organized community effort.

In these heart disease control programs, "prevention" is the key word. "Characteristically," writes Lester Breslow, chief of California's bureau of chronic diseases, "the public health approach to problems stresses prevention. Is applied to heart disease and other chronic diseases, prevention includes measures which avert the occurrence of disease (primary prevention) and those which halt or retard the progression of disease into disability or premature death (secondary prevention)."

However much a health department is able to do now, and does do, it can be sure of having the help and support of its neighboring heart association. Heart association and health department alike are both working toward the prevention, in its broadest sense, of cardiovascular disease.

\section{REFERENCES}

(1) Stop rheumatic ferer-Health education unit. Pub. Health Rep. 70: 508, May 1955.

(2) Mattison, B. F.: Enidemiological techniques and data in planning public health programs. Pub. Health Rep. 70: 625-632, July 1955. 